\title{
Nonlinear finite element analysis of punching shear strength of reinforced concrete slabs supported on L-shaped columns
}

\author{
Qing Zhang', Graeme J. Milligan², Maria Anna Polak ${ }^{3}$ \\ ${ }^{1}$ Department of Civil and Environmental Engineering (CEE); University of Waterloo; \\ 200 University Avenue West, Waterloo, Ontario, Canada; paris.zhang@uwaterloo.ca \\ ${ }^{2}$ Department of Civil and Environmental Engineering (CEE); University of Waterloo; \\ 200 University Avenue West, Waterloo, Ontario, Canada; gjmillig@uwaterloo.ca \\ ${ }^{3}$ Department of Civil and Environmental Engineering (CEE); University of Waterloo; \\ 200 University Avenue West, Waterloo, Ontario, Canada; polak@uwaterloo.ca
}

Funding: This work was supported by the Natural Sciences and Engineering Research Council of Canada (NSERC) and the University of Waterloo.

Abstract: Most current concrete design codes include provisions for punching shear of reinforced concrete slabs supported on columns with L, T, and cruciform shapes. Reference studies verifying the accuracy of these code provisions are typically not provided. Empirical data of punching failures of slabs supported on columns with L, T, and cruciform shapes are limited due to the cost and time required to test specimens with slab thicknesses and column sizes commonly used in practice. In this paper, the punching shear behaviour of five interior L-shaped slab-column connections, one without a slab opening and four with slab openings, subjected to static concentric loading are analyzed using a plasticity-based nonlinear finite element model (FEM) in ABAQUS. The FEM is similar to models previously calibrated at the University of Waterloo and was calibrated considering nine slabs that were tested to study the impact of column rectangularity on the punching shear behaviour of reinforced concrete slabs. The finite element analysis results indicate that shear stresses primarily concentrate around the ends of the L, and that current code predictions from ACI 318-19 and Eurocode 2 may be unconservative due to the assumed critical perimeters around L-shaped columns.

Keywords: punching shear, finite element analysis, L-shaped columns, slab openings

\section{Introduction}

Due to the complicated three-dimensional state of stress in the vicinity of the columns, reinforced concrete slabs supported on columns are susceptible to brittle punching shear failures. For slab-column connections without shear reinforcement, a punching shear failure occurs when the shear stresses due to the applied loads exceed the shear strength provided by 
the concrete. Due to the brittle nature of the failure, a punching failure of one slab-column connection can lead to the progressive collapse of an entire structure.

Much research has been dedicated to the study of the punching shear behaviour of reinforced concrete flat slabs due to the brittleness of the failure. The majority of this past research has been experimental, and has involved the testing of isolated slab-column connections, where the portion of the slab included in the test approximates the negative moment area around the column. Even though the existing experimental punching shear database is extensive [1], [2], not all parameters have been sufficiently studied. For example, the punching shear behaviour of reinforced concrete slabs supported on L, T, and cruciform-shaped columns has received limited attention [3], [4] even though most current worldwide design codes include provisions for these column shapes [5], [6]. The derivation and reasoning behind these code provisions are unclear.

Empirical tests of slabs supported on L, T, or cruciform-shaped columns are limited due to the cost and time required to test specimens with slab thicknesses and column sizes seen in practice. Additionally, the measurement of quantities, such as the shear stress distribution in the slab, can be difficult in experiments, making it complicated to identify the portion of the slab and column which are effective in transferring loads. Nonlinear finite element analysis (FEA), calibrated to the results of experimental tests, can be used to efficiently supplement the existing experimental database, and allows for detailed investigations of the influence of specific parameters and the internal stress distribution in the slab.

In this paper, the punching shear behaviour of interior L-shaped slab-column connections subjected to static concentric loading with or without openings in the slab is analyzed using a three-dimensional nonlinear finite element model (FEM) implemented in ABAQUS using the Concrete Damaged Plasticity Model. The FEM used in this work is similar to other models used to study punching shear at the University of Waterloo [7], and it was calibrated considering the nine isolated interior slab-column connections tested by Hawkins, Fallsen, and Hinojosa [8]. These nine slab-column specimens were tested to study the influence of the column aspect ratio, $\beta$, on punching shear capacity, and the test results form the basis of the ACI 318-19 provisions relating punching capacity to $\beta$ [5], [9]. As will be discussed herein, the ACI 318-19 provisions for square, rectangular, or L-shaped columns are the same, other than the shape of the assumed critical perimeter and calculation of $\beta$ for L-shaped columns.

The punching shear provisions from ACI 318-19 [5] and Eurocode 2 [6] are evaluated by comparing the code and FEM predictions for five slabs supported on L-shaped columns, four of which have openings in the slab near the column. Additionally, the applicability of the assumed critical perimeter around L-shaped columns is investigated through an analysis of the slab shear stress distribution along the column perimeter. A brief discussion of the FEM calibration is also provided.

\section{Punching shear design of L-shaped slab-column connections according to ACI 318-19 and Eurocode 2 (2004)}

In punching shear design, the shear stress due to the applied load and shear stress resistance along a critical perimeter located at some distance from the column face are typically assumed to be constant. In ACI 318-19 [5] and Eurocode 2 [6], the critical perimeter for slab-column connections without shear reinforcement typically has the same shape as the column and is located at a distance of $d / 2$ and $2 d$ from the column face respectively. However, for L-shaped columns, the critical perimeter assumed in both codes does not follow the column perimeter, and is instead based on an assumed effective loaded area as shown in Fig. 1a. 
Previous FEA of slabs supported on rectangular columns [10] and walls [11] has shown that the shear stresses along the column perimeter and the critical perimeters assumed in design codes, mainly that assumed in ACI 318-19 [5], are non-uniform and typically concentrate along the short sides and near the corners of the column. Similar stress concentrations are expected for slabs supported on L-shaped columns, and as such, it is hypothesized that the diagonal portion of the critical perimeter shown in Fig. 1a is ineffective in resisting punching shear.

a) Unreinforced Slab-Column Connection L-Shaped Column

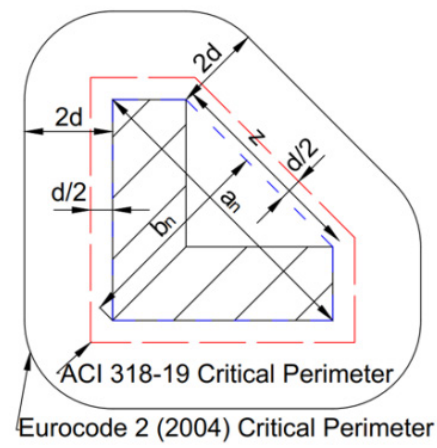

b) Shear Stud Reinforced Slab-Column Connection, Cruciform Layout

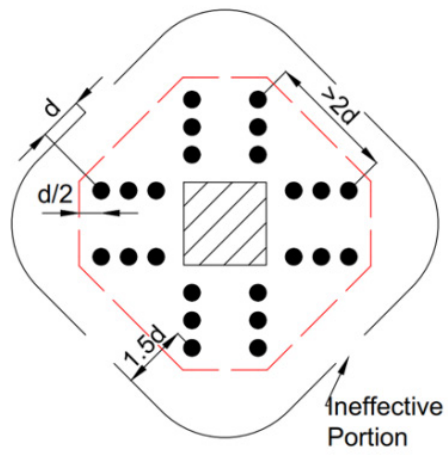

Fig. 1. Critical perimeters assumed in ACI 318-19 [5] and Eurocode 2 [6]: a) around L-shaped columns, b) shear-reinforced connection with cruciform layout. Source: own study based on [5], [6]

Additionally, Eurocode 2 [6] assumes that the entire critical perimeter is effective for L-shaped slab-column connections without shear reinforcement. This contrasts with the assumed critical perimeter around slab-column connections with shear reinforcement arranged in a cruciform layout, where the diagonal distance between the outer shear reinforcement on adjacent sides of the column exceeds $2 d$. When the diagonal distance between shear reinforcement on adjacent sides of the column exceeds $2 d$, Eurocode 2 ([6]) assumes the reduced effective critical perimeter shown in Fig. 1b. This reduced critical perimeter accounts for large unreinforced portions of the slab near the column. However, no similar reduction is stated for unreinforced L, T, or cruciform-shaped slab-column connections where the diagonal distance between the inner flange edges, $z$ (see Fig. 1a), exceeds $2 d$. If an effective critical perimeter applies for the unreinforced portions of shear-reinforced slab-column connections, a similar reduction should apply to L-shaped columns with a large unreinforced zone between the column flanges.

In ACI 318-19 [5] the nominal shear capacity along the critical perimeter, $v_{\mathrm{c}}$ is calculated as the minimum of Eqs 1-3 regardless of the column shape:

$$
\begin{aligned}
& 0.33 \lambda \lambda_{s} \sqrt{f_{c}^{\prime}} \\
& 0.17(1+2 / \beta) \lambda \lambda_{s} \sqrt{f_{c}^{\prime}} \\
& 0.083\left(2+\alpha_{s} d / b_{o}\right) \lambda \lambda_{s} \sqrt{f_{c}^{\prime}}
\end{aligned}
$$

where $\lambda$ is a parameter accounting for concrete density, $\lambda_{\mathrm{s}}$ is the size effect factor, $f_{\mathrm{c}}^{\prime}$ is the concrete compressive strength (MPa), $\alpha_{\mathrm{s}}$ is a term dependent on the column location, $d$ is the effective slab depth $(\mathrm{mm})$ and $b_{\mathrm{o}}$ is the critical perimeter length $(\mathrm{mm})$. Eq. 2 , which relates the nominal shear capacity to the column aspect ratio, $\beta$, was primarily derived from the results of 
nine isolated slab-column tests by Hawkins, Fallsen, and Hinojosa [5], [8], [9]. Due to the lack of experimental tests of slabs supported on L-shaped columns, and since Eq. 2 is applied to both rectangular and L-shaped columns, these experimental tests, which are summarized in Section 3.2, form the basis of the FEM used in this study. For slabs supported on rectangular columns, $\beta$ is defined as the ratio of the maximum and minimum column dimensions, but for slabs supported on L-shaped columns, $\beta$ is defined as $a_{\mathrm{n}} / b_{\mathrm{n}}$, where $a_{\mathrm{n}}$ and $b_{\mathrm{n}}$ are defined as shown in Fig. 1a. As such the effective aspect ratio for L-shaped columns is significantly lower than the aspect ratio of the individual rectangular portions which make up the L-shape, which causes Eq. 2 to predict much higher nominal shear stress capacities.

\section{FEA of L-shaped slab-column connections}

\subsection{Study overview}

To verify if the diagonal portion of the critical perimeter around L-shaped columns assumed in ACI 318-19 [5] and Eurocode 2 [6] is effective in resisting punching shear, the four isolated slab-column specimens shown in Fig. 2, and one specimen without an opening in the slab are analyzed using the calibrated FEM discussed in the next section of this paper. Since the overall accuracy of the code provisions for L-shaped columns is unknown, three of the analyzed specimens contain openings in the slab between the column flanges. If the portion of the slab in the vicinity of the diagonal portion of the critical perimeter is ineffective in transferring loads between

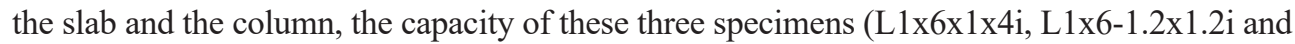
L1 6 6-1.2x1.2o) should be similar to that of the connection without an opening, L1 x6-0.
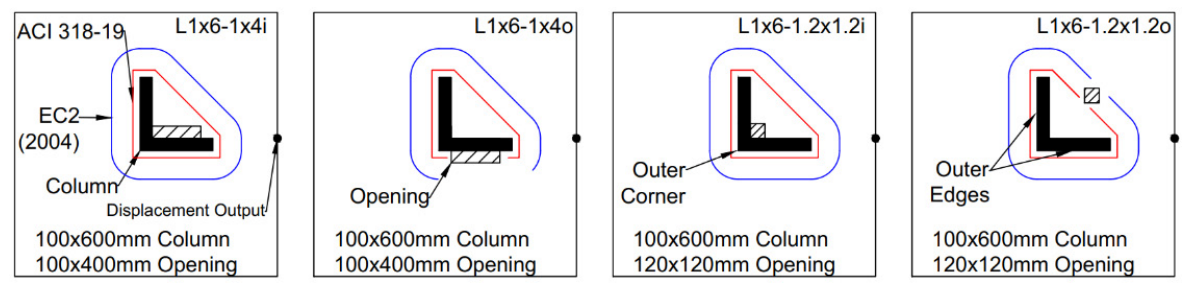

Fig. 2. Slab-column specimens studied and critical perimeters used to calculate capacities according to ACI 318-19 [5] and Eurocode 2 [6] (specimen without opening, L1x6-0 not shown). Source: own study

If the capacity of the three specimens with openings between the column flanges is similar to that of the specimen without an opening, it proves that the diagonal portion of the critical perimeter is ineffective and should be neglected in the calculation of punching capacity. However, if this portion of the critical perimeter is ineffective, openings could be located in the region between the column flanges with a minimal impact on the connection's punching capacity, which is a significant benefit compared to slabs supported on square or rectangular columns, where the introduction of an opening near the column typically results in a significant decrease in capacity. Additionally, locating openings between the column flanges would allow the equipment or pipes requiring the openings in the slab to be easily concealed. 


\subsection{Overview of FEM}

The punching shear behaviour of special-shaped slab-column connections has not been extensively studied, even though these connections were proven to have good seismic performance [3] and higher ductility and strength than conventional square slab-column connections [4]. Since previous experiments of slabs supported on L-shaped columns are limited, the FEM used in this study was calibrated based on the results of nine isolated slab-column tests performed by Hawkins et al. [8] focussed on determining the impact of the column aspect ratio, $\beta$, on punching shear behaviour.

The nine specimens tested by Hawkins et al. [8] are summarized in Tab. 1. All slabs were $2133.6 \mathrm{~mm}$ square in plan, $152.4 \mathrm{~mm}$ thick, and supported on rectangular columns located at the slab center. The investigated parameters included the column aspect ratio, $\beta$, concrete compressive strength, the loading pattern and the flexural reinforcement. The column length was $1041.4 \mathrm{~mm}$ for all nine specimens, and the column aspect ratio varied between 1 and 4.33. For slabs 1 through 6, eight equal concentrated loads were applied to the slab edges parallel to the short side of the column, except for slab 6 , where the loads were applied on the slab edges parallel to the long side of the column. The eight equal concentrated loads are labelled as P in Fig. 3. For slabs 7-9, four additional concentrated loads were applied to the slab edges parallel to the long side of the column. The magnitude of each of these additional loads was $65 \%$ of the loads on the other slab edges, as shown in Fig. 3. The flexural reinforcement also varied between the slabs. One flexural reinforcement layout was used for slabs 1-4 and 6, and modified layouts were used for all remaining slabs. The parameters investigated included the flexural reinforcement ratio, effective depth, spacing and adding additional reinforcement in the vicinity of the column. For all slabs, the top reinforcement layer was placed in the direction of the P loads. A summary of the experimental setup is shown in Fig. 3a, and the modified slab dimensions used in the L-shaped column study are shown in Fig. 3b. The reasoning behind these modifications is discussed at the end of this section. The reinforcement layout for slab 1 was used in the L-shaped column study.

Table 1. Summary of slabs tested by Hawkins et al. [8] and FEA predictions. Source: own study

\begin{tabular}{llllllll}
\hline \multicolumn{3}{l}{$\begin{array}{l}\text { Column Dimensions } \\
\left(c_{\min } \times c_{\max }\right)\end{array}$} & & $f_{\mathrm{c}}(\mathrm{MPa})$ & $d(\mathrm{~mm})^{(\mathrm{d})}$ & $V_{\text {exp }}(\mathrm{kN})$ & \multicolumn{2}{l}{$V_{\text {FEA }}(\mathrm{kN})$} \\
\cline { 1 - 7 } Slab & Original & Modified & & & & & (b) \\
\hline 1 & $304.8 \times 304.8$ & $320 \times 320$ & $30.3^{\text {(c) }}$ & 117.3 & 383.9 & 326.0 & 336.8 \\
\hline 2 & $203.2 \times 406.2$ & $200 \times 400$ & 26.3 & 117.3 & 351.4 & 331.3 & 332.2 \\
\hline 3 & $152.4 \times 457.2$ & $160 \times 480$ & 32.0 & 117.3 & 333.2 & 339.9 & 351.8 \\
\hline 4 & $114.3 \times 495.3$ & $120 \times 480$ & 31.0 & 117.3 & 330.5 & 331.8 & 337.2 \\
\hline 5 & $152.4 \times 457.2$ & $160 \times 480$ & 26.9 & 117.3 & 355.0 & 325.8 & 332.6 \\
\hline 6 & $152.4 \times 457.2$ & $160 \times 450$ & 22.7 & 117.3 & 335.8 & 300.9 & 308.2 \\
\hline 7 & $152.4 \times 457.2$ & $160 \times 480$ & 25.9 & 117.3 & 319.8 & 297.7 & 307.3 \\
\hline 9 & $114.3 \times 495.3$ & $120 \times 480$ & 26.1 & 120.65 & 314.5 & 292.5 & 298.4 \\
\hline
\end{tabular}

(a) FEA predicted capacity considering specific slab parameters

(b) FEA predicted capacity considering modified slab and column dimensions

(c) used in analysis of L-shaped column specimens

(d) slab thickness, $h$, of $152.4 \mathrm{~mm}$ and column height of $1041.4 \mathrm{~mm}$ in original calibration, $h$ and column height modified to $152 \mathrm{~mm}$ and $1068 \mathrm{~mm}$ respectively for $V_{\mathrm{FEA}}{ }^{(b)}, d=117 \mathrm{~mm}$ for all specimens for $V_{\mathrm{FEA}}{ }^{(\mathrm{b})}$, modified $d, h$ and column height used in L-shaped column study 
a)

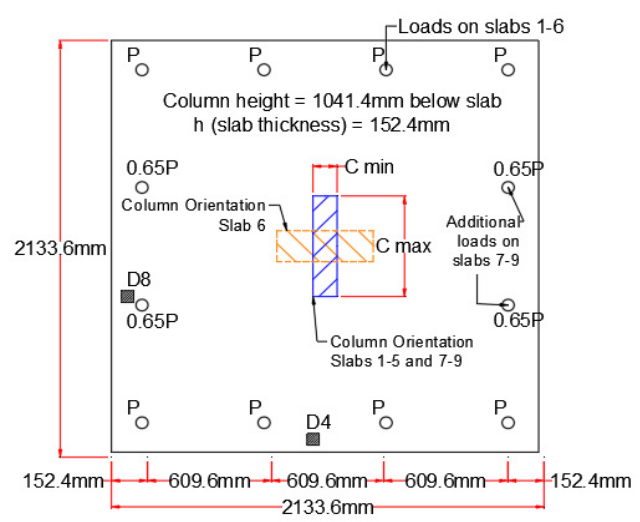

b)

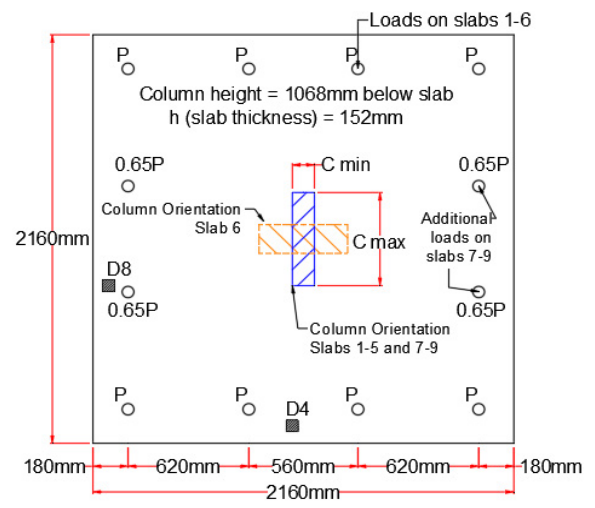

Fig. 3. a) Experimental specimen dimensions and loading [8], b) modified dimensions

* Note: in L-shaped column study, all concentrated loads have equal magnitude. Source: own study

In the FEM the concrete slab and column are discretized using three-dimensional, eightnode, hexahedral continuum reduced integration elements (C3D8R) and the steel reinforcement is discretized using three-dimensional, two-node linear truss elements (T3D2). Only a quarter of the slab-rectangular-column connections are modelled, taking advantage of symmetry, as shown in Fig. 4. For the L-shaped slab-column connections, the full isolated slab-column connection is modelled, and the symmetry boundary conditions used in the quarter model are removed.

Based on a comparison of the FEA predictions and experimental results, the parameters of the FEM were calibrated. A summary of the calibrated concrete parameters is provided in Tab. 2. The flexural reinforcement was modelled as linear-elastic perfectly plastic, with a yield strength of $414 \mathrm{MPa}$, Elastic Modulus of $200000 \mathrm{MPa}$ and Poisson's ratio of 0.3. Applying the calibrated FEM to all nine specimens results in a maximum underprediction of $15.1 \%$ and a maximum overprediction of $2.0 \%$ compared to the experimental capacities. The predicted failure modes and crack patterns also agree with the experimental observations of Hawkins et al. [8].

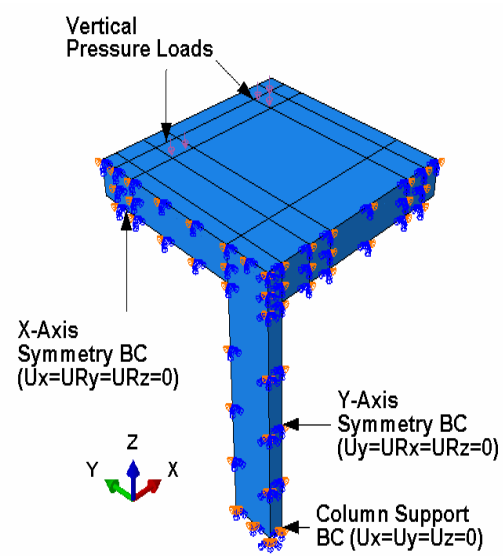

Fig. 4. General boundary conditions used in FEM (slab 3 shown), $1 / 4$ models used in calibration, full slab specimen used in L-shape column study. Source: own study 
Table 2. Summary of concrete parameters in calibrated model. Source: own study

\begin{tabular}{lll}
\hline $\begin{array}{l}\text { Material Model }- \text { Concrete } \\
\text { Damaged Plasticity }\end{array}$ & $\begin{array}{l}\text { Uniaxial Compression Model }- \text { Hognestad } \\
\text { Parabola }\end{array}$ & Element Size $-20 \mathrm{~mm}$ \\
\hline Dilation Angle $-42^{\circ}$ & $E_{c}=5000 \sqrt{f_{c}^{\prime}}(\mathrm{MPa})$ & Element Type - C3D8R \\
\hline Eccentricity* -0.1 & Poisson's Ratio $(v)-0.2$ & \\
\hline$\sigma_{b o} / \sigma_{c o} *-1.16$ & $\begin{array}{l}\text { Tension Model }- \text { Bilinear tensile stress- } \\
\text { crack width [12] }\end{array}$ & *ABAQUS Default \\
\hline Damage Parameters - N.A. & $G_{f}=0.08 \mathrm{~N} / \mathrm{mm}$ & \\
\hline
\end{tabular}

A comparison of the experimentally measured and FEA predicted load-displacement responses for slab 1 at the locations D4 and D8, as shown in Fig. 3 is provided in Fig. 5. It should be noted that the load-displacement response provided by Hawkins et al. [8] did not extend to the measured capacity, whereas the FEA predictions are included until the peak capacity predicted by the FEA. Even though the experimental curves are incomplete, important conclusions can be drawn. The calibrated FEM predicts a higher initial stiffness, likely due to the assumed uniaxial compressive stress-strain relationship for the concrete and due to the lack of temperature and shrinkage cracking in the FEM. However, the FEM predicts a similar stiffness to that measured experimentally in the plastic portion of the response.

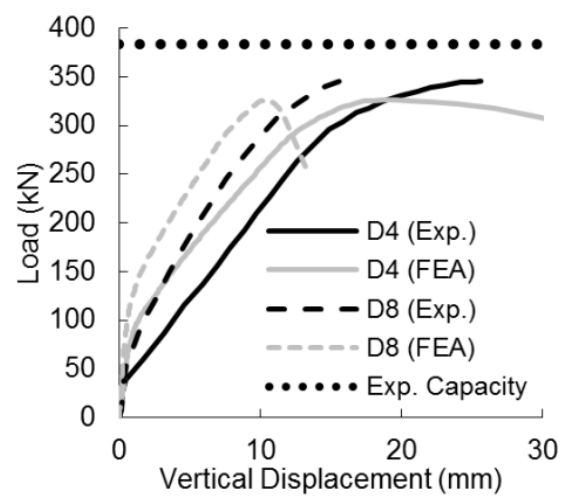

Fig. 5. Comparison of the experimental and FEA load-displacement curves for slab 1. Source: own study (experimental data based on [8])

A comparison of the load-displacement response in the loaded and unloaded directions predicted by the calibrated FEM for slabs 1-6 and slabs 7-9 are provided in Fig. 6a, and Fig. 6b, respectively. For slab 1-6, which were loaded in one-way action, the FEM predicts a similar stiffness for all six slabs and a higher stiffness in the unloaded direction. A higher stiffness in the unloaded direction was also observed by Hawkins et al. [8] Unlike slabs $1-6$, the predicted stiffness of slabs 7-9 is similar in both directions. The load-displacement response for slab 7 provided by Hawkins et al. [8] also displays similar stiffness in both directions, with the stiffness in the direction perpendicular to the short side of the column (D4) being slightly higher. 
a) Slabs 1-6

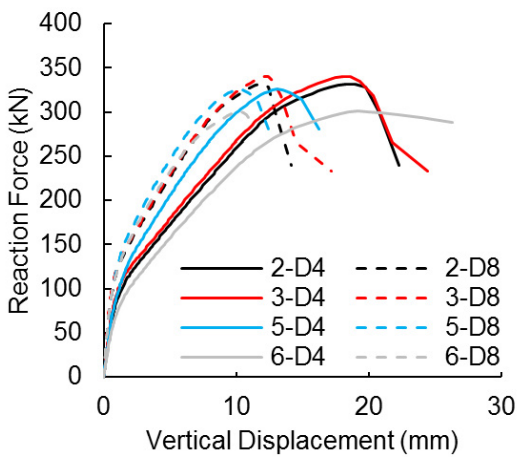

b) Slabs 7-9

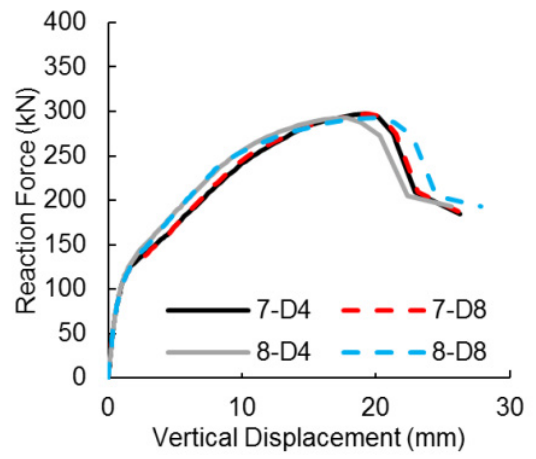

Fig. 6. Representative load-displacement curves at D4 and D8 locations for: a) slabs 1-6, b) slabs 7-9. Source: own study

As previously stated, the calibrated FEM is based on the Concrete Damaged Plasticity Model available in ABAQUS. This material model accounts for concrete cracking through a smeared crack approach, making the model results mesh size-dependent [14]. As mentioned previously, a global mesh size of $20 \mathrm{~mm}$ was found to result in the best correlation between the experimental and numerical results. In order to improve the mesh uniformity in the L-shaped column study, the slab dimensions, column dimensions and loading points were modified as summarized in Tab. 1, and Fig. 3b. The impact of these modifications for the Hawkins et al. [8] slabs was minor as shown in Tab. 1. The modified slab dimensions, column height, effective depth and loading point locations are used in the L-shaped column study, with equal loading applied on each point, as shown in Fig. 3 b.

\subsection{FEM results}

Punching shear failures were predicted for all five specimens with L-shaped columns. On the tension surface of the slab there was a large concentration of cracks near the outer corner and along the outer edges of the L shape (outer corner and edges are labelled in Fig. 2). This cracking concentration suggests that a large portion of the total load is transferred along the outer edges of the L shape.
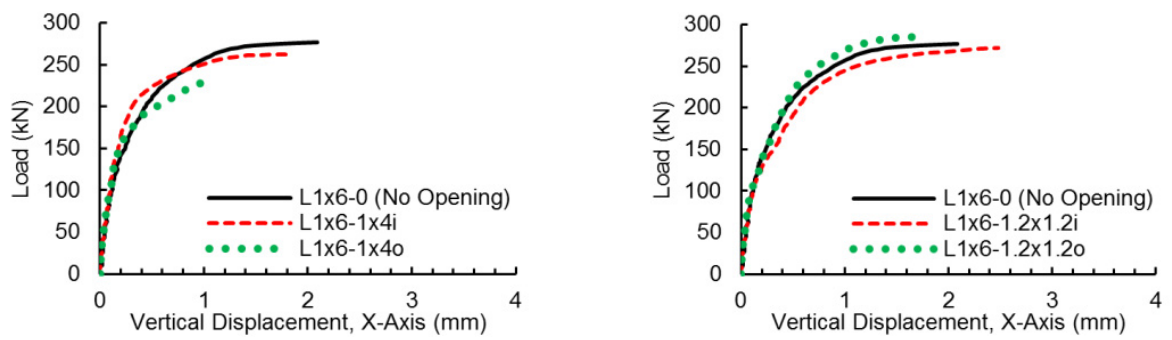

Fig. 7. Comparison of predicted-load displacement response (displacement location shown in Fig. 2). Source: own study

A comparison of the predicted load-displacement response for all five specimens, where the displacement is measured at the location shown in Fig. 2, is provided in Fig. 7, and the 
capacities of each specimen predicted by the calibrated FEM are provided in Tab. 3. As expected the impact of openings located between the column flanges is minor, with a maximum decrease in punching capacity of $5.2 \%$ predicted for specimen L1x6-1x4i, compared to a decrease of $16.2 \%$ for the same opening size located on the outer edge of the column (L1x6-1x4o). This large decrease in capacity for an opening located on the outer edge of the column compared to openings located between the flanges supports the hypothesis that the diagonal portion of the critical perimeter assumed in ACI 318-19 [5] and Eurocode 2 [6] is ineffective in resisting punching shear.

Table 3. Comparison of punching capacity predicted by FEM, ACI 318-19 [5] and Eurocode 2 [6]. Source: own study

\begin{tabular}{|c|c|c|c|c|c|c|}
\hline Specimen & Opening Size & $V_{\mathrm{FEA}}(\mathrm{kN})$ & & $(\mathrm{kN})$ & & $(\mathrm{kN})$ \\
\hline L1x6-0 & None & 277.1 & 523.3 & $382.4 * *$ & 479.1 & $384.4 * *$ \\
\hline L1x6-1x4i* & $100 \times 400$ & 262.7 & 523.3 & $382.4 * *$ & 479.1 & $384.4 * *$ \\
\hline L1x6-1x4o & $100 \times 400$ & 232.1 & 436.3 & $275.7 * *$ & 372.1 & $277.4 * *$ \\
\hline L1x6-1.2x1.2i* & $120 \times 120$ & 271.7 & 523.3 & $382.4 * *$ & 479.1 & $384.4 * *$ \\
\hline L1x6-1.2x1.2o & $120 \times 120$ & 284.9 & 509.6 & $382.4 * *$ & 450.7 & $384.4 * *$ \\
\hline
\end{tabular}

An analysis of the shear stress distribution in the slab along the column perimeter further supports the hypothesis that the diagonal portion of the critical perimeter is ineffective. The shear stress distributions along the column perimeter predicted by ABAQUS for specimen L1x6-0 and L1x6-1x4o are provided in Fig. 8. As expected, shear stress concentrations at the column corners are predicted, and the shear stress magnitudes on the outer edges of the $\mathrm{L}$ are typically higher than those on the inner edges. However, unlike slabs supported on rectangular columns, only a very small amount of the total force is transferred along the short sides of the column, with the majority of the force being transferred along the outer edges of the column.

a)

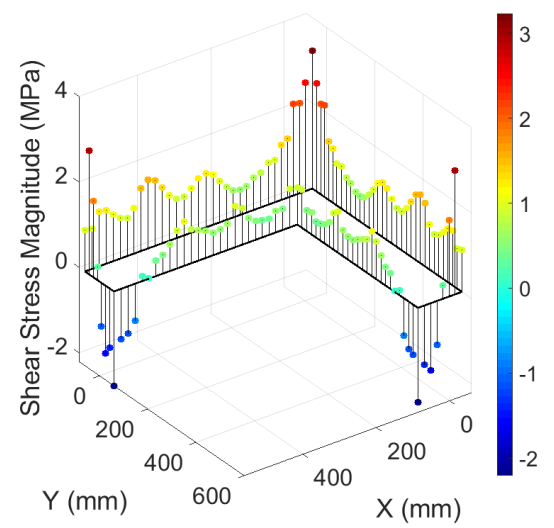

b)

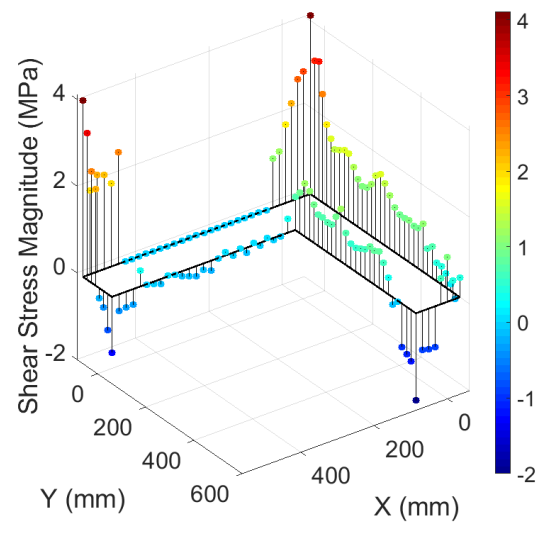

Fig. 8. Shear stress distribution along column perimeter: a) L1x6-0, b) L1x6-1x4o, 100\% of peak load. Source: own study 
A comparison of the punching capacities predicted by the FEM, ACI 318-19 [5] and Eurocode 2 [6] is also provided in Tab. 3. As seen in Tab. 3, both the ACI 318-19 [5] and Eurocode 2 [6] provisions greatly overpredict the punching capacities predicted by the FEM for the five specimens, with ACI 318-19 [5] being more unconservative than Eurocode 2 [6]. Even if the diagonal portion of the critical perimeter assumed in both codes is neglected, both codes are still unconservative compared to the FEM predictions demonstrating that the punching behaviour of slabs supported on L-shaped columns is not accurately captured by either code. It is interesting to note that if the diagonal portion of the critical perimeter is neglected, both codes result in similar punching capacity predictions.

\section{Conclusions}

In this paper, the punching shear behaviour of five interior L-shaped slab-column connections, one without a slab opening near the column and four with slab openings, subjected to concentric vertical loading are analyzed using a plasticity-based three-dimensional nonlinear FEM in ABAQUS. The FEM, calibrated considering experimental results of nine interior slab-rectangular column connections, was used to verify the critical perimeter around L-shaped columns assumed in ACI 318-19 [5] and Eurocode 2 [6]. From the presented work, the following conclusions can be drawn:

1. The results of the FEA suggest that the effective critical perimeter around L-shaped columns assumed in ACI 318-19 [5] and Eurocode 2 [6] are incorrect. The capacity of the specimen without an opening is similar to that for the three specimens with openings located in between the flanges of the L. This similarity in capacity suggests that the diagonal portion of the critical perimeter is ineffective in resisting punching shear. The shear stress distributions along the column perimeter predicted by ABAQUS support the conclusion that the diagonal portion of the critical perimeter is ineffective. The predicted shear stress magnitudes along the inner sides of the L-shaped column are typically lower than those along the outer sides of the column, which demonstrates that the outer portion is more effective.

2. The punching provisions for L-shaped columns in ACI 318-19 [5] and Eurocode 2 [6] appear to be unconservative for connections with and without openings. Further analysis of multiple column sizes is required but the code predictions, even with the diagonal portion of the critical perimeter neglected, are unconservative compared to the FEA results for all five analyzed specimens.

3. The ideal location for an opening near an L-shaped slab-column connection is within the region between the column flanges as it minimizes the impact of the opening on punching capacity, while also allowing the equipment or pipes requiring the opening to be easily concealed.

\section{References}

[1] FIB, "Punching of structural concrete slabs", fib Bulletin 12, 2001.

[2] Ospina C.E., Birkle G., Widianto Y.W. et al., "NEES: ACI 445 Punching Shear Collected Databank", 2015.

[3] Wang Z.-j., Liu W.-q., Wang J., Jing Y.-s. and Xu C., "Shaking table test for a mid-highrise big-bay RC frame model", Earthquake Engineering and Engineering Vibration, vol. 19, no. 3, 1999, pp. 59-64 (in Chinese). 
[4] Liu W. and Huang C., "Experimental investigation on punching shear behaviour of concrete slab-nonrectangular column connections", Journal of Building Structures, vol. 25, no. 4, 2004, pp. 26-33, (in Chinese).

[5] ACI Committee 318, Building Code Requirements for Structural Concrete (ACI 318-19) and Commentary on Building Code Requirements for Structural Concrete (ACI 318R-19), Farmington Hills, MI: American Concrete Institute, 2019.

[6] European Committee For Standardization, Eurocode 2: Design of concrete structures - Part 1-1: General Rules and Rules for Buildings, Brussels, Belgium, 2004.

[7] Genikomsou A.S., Milligan G.J. and Polak M.A., "Modeling Parameters in Punching Shear Finite Element Analysis of Concrete Slabs", ACI Special Publication, vol. 328, 2018, pp. 12.1-12.24.

[8] Hawkins N.M., Fallsen H.B. and Hinojosa R.C., "Influence of Column Rectangularity on the Behavior of Flat Plate Structures”, ACI Special Publication, vol. 30, 1971, pp. 127-146.

[9] ASCE-ACI Committee 426, "The shear strength of reinforced concrete members - slabs", Journal of the Structural Divison, vol. 100, no. 8, 1974, pp. 1543-1591.

[10] Milligan G.J. and Polak M.A., "Finite Element Investigation on the Effect of Column Rectangularity on Punching Shear Strength of Concrete Slabs, The International Federation for Structural Concrete", in fib Congress, Melbourne, 2018, p. 12.

[11] Milligan G.J. and Polak M.A., "Finite Element Analysis of Shear Behaviour of Concrete Slabs Partially Supported on Walls", in Concrete innovations in materials, design and structures: proceedings of the 2019 fib symposium, held in Krakow, Poland, May 27-29, 2019, Kraków, 2019, pp. 1803-1810.

[12] Petersson E., Crack Growth and Development of Fracture Zones in Plain Concrete and Similar Materials. Division of Building Materials, LTH, Lund, Sweden, 1981.

[13] Dassault Systemes Simulia Corp., ABAQUS Analysis User's Manual 6.12-3, Providence, RI, USA, 2012.

[14] Genikomsou A.S. and Polak M.A., "Finite element analysis of punching shear of concrete slabs using damaged plasticity model in ABAQUS", Engineering Structures, vol. 98, 2015, pp. 38-48. https://doi.org/10.1016/j.engstruct.2015.04.016 
